\title{
Seismicity Variations Associated with Aseismic Transients in Guerrero, Mexico, 1995-2006
}

\section{Citation}

Liu, Yajing, James R. Rice, and Kristine M. Larson. 2007. Seismicity variations associated with aseismic transients in Guerrero, Mexico, 1995-2006. Earth and Planetary Science Letters, 262(3-4): 493-504.

\section{Published Version}

http://dx.doi.org/10.1016/j.epsl.2007.08.018

\section{Permanent link}

http://nrs.harvard.edu/urn-3:HUL.InstRepos:2623550

\section{Terms of Use}

This article was downloaded from Harvard University's DASH repository, and is made available under the terms and conditions applicable to Other Posted Material, as set forth at http:// nrs.harvard.edu/urn-3:HUL.InstRepos:dash.current.terms-of-use\#LAA

\section{Share Your Story}

The Harvard community has made this article openly available.

Please share how this access benefits you. Submit a story.

\section{Accessibility}




\title{
Seismicity variations associated with aseismic transients in Guerrero, Mexico, 1995-2006
}

\author{
Yajing Liu ${ }^{\mathrm{a}, *}$, James R. Rice ${ }^{\mathrm{a}, \mathrm{b}}$, and Kristine M. Larson ${ }^{\mathrm{c}}$
}

${ }^{a}$ Department of Earth and Planetary Sciences, Harvard University, Cambridge, MA 02138, USA.

${ }^{\mathrm{b}}$ School of Engineering and Applied Sciences, Harvard University, Cambridge, MA 02138, USA.

${ }^{\mathrm{c}}$ Department of Aerospace Engineering Sciences, University of Colorado, Boulder, CO 80309, USA. 


\section{Abstract}

Primarily aseismic deformation transients in subduction zones, sometimes asso3 ciated with tremors and low-frequency earthquakes, are a newly recognized mode 4 of deformation. Stressing in the up-dip seismogenic zone is increased episodically 5 due to down-dip transient slips, and each event may make it more prone to fail6 ure in a large thrust earthquake. It is important for seismic hazard assessment to 7 search and identify patterns of seismicity variation associated with transients. The 8 Guerrero, Mexico, region is chosen for this study because of long-term continuous 9 geodetic observations and abundant seismicity in the shallow subduction zone. We search the GCMT and NEIC catalogs for earthquakes with depths less than 100 $11 \mathrm{~km}$ between 1995 and 2006 within the area covering the region affected by major transients since 1996. A completeness magnitude of $M_{c}=4.5$ is determined for the 13 NEIC catalog used in this study, based on the maximum likelihood method.

Three large transients in 1998, 2001-2002 and 2006 are all temporally correlated with high seismic rates in the studied area. In particular, transients are either pre16 ceded by a cluster of extensional earthquakes relatively far inland from the trench, 17 or followed by shallow thrust earthquakes close to the trench. In some cases, such as the 2001-2002 transient, both types of activity are found bordering the transient. communication between distant seismicity clusters in shallow subduction zones.

Key words:

22 Aseismic transient, Seismicity variation, Guerrero subduction zone

\footnotetext{
* Corresponding author.

Email addresses: liu@esag.harvard.edu (Yajing Liu), rice@esag.harvard.edu (James R. Rice), kristinem.larson@gmail.com
} 
Aseismic transients with as yet no obvious relation to large earthquakes are a newly recognized mode of deformation along major fault zones. Short-period transients (several months to years) have recently been detected in shallowdipping subduction zones, such as Alaska-Aleutian [Ohta et al., 2006], Cascadia [Dragert et al., 2001; Rogers and Dragert, 2003; Szeliga et al., 2004; McCausland et al., 2005], Guerrero, Mexico [Lowry et al., 2001; Kostoglodov et al., 2003; Larson et al., 2004; Lowry, 2006], Hikurangi, New Zealand [Douglas et al., 2005; Wallace and Beavan, 2006], central and southwest Japan [Hirose et al., 1999; Ozawa et al., 2002; Hirose and Obara, 2005], along the San Andreas Fault [Murray and Segall, 2005] and on a detachment beneath the south flank of Kilauea volcano [Segall et al., 2006]. Natawidjaja et al. [2004; 2007] also suggested the occurrence of aseismic slip episodes, in 1962, 1968, 1975 and 1984, on the Sunda Megathrust along the coast of Sumatra, based on the annual banding of corals, and Meltzner et al. [2007] have noted coral evidence for an aseismic uplift event in late 2003 in central Simeulue Island between the December 2004 and March 2005 megathrust slip zones. Aseismic transients in some subduction zones are accompanied by deep non-volcanic tremors, which are difficult to locate due to lack of distinct $\mathrm{P}$ or S-wave arrivals. Tremors or low-frequency earthquakes, which are possibly components of tremor sequences, may be distributed over a broad depth range [northern Cascadia, Kao et al., 2005], or clustered in a tabular zone along the thrust interface [Shikoku, SW Japan, Shelly et al., 2006] at the depths where transient deformation is inferred to take place.

(Kristine M. Larson). 
47 Transient deformation is estimated to be due to slow slips down-dip from the

48 locked region. Stressing in the up-dip seismogenic zone is increased episodi-

49

cally, and each transient can make it more prone to failure in a large thrust earthquake. Thus, it is very important for seismic hazard assessment [Mazzotti and Adams, 2004] to search and identify patterns of spatiotemporal seismicity variation associated with transients. Such patterns are indeed detected for some regions. For example, Segall et al. [2006] reported swarms of highfrequency earthquakes, which accompanied, and are hypothesized to be triggered by silent slip events on Kilauea volcano, Hawaii. During the Tokai slow slip event [Ozawa et al., 2002; 2005], Yoshida et al. [2006] reported variations in the slab and crustal seismicity concurrent with changes in the plate slip velocity. Liu and Rice [2005] noted that the initiation of the large 2001-2002 transient in Guerrero, Mexico, coincided with two normal-faulting earthquakes of $M_{w}=5.0$ and 5.8 relatively far inland from the trench, and the transient was followed by several thrust earthquakes closer to the trench. The 2001-2002 large transient was suggested to act as a spatial-temporal connection between the two clusters of seismicity. Repeated episodes of apparent switching between down-dip and up-dip earthquake activity have earlier been reported by Dmowska et al. [1988] for other regions that have hosted large earthquakes along the Middle America trench (MAT). They suggested earthquakes near the down-dip end of the locked seismogenic zone as a mechanism of communication between these seismicity clusters.

The above observed connections between transients and seismicity motivated us to systematically investigate their relation in a region with long-term continuous geodetic measurements and abundant seismicity. Guerrero, Mexico, appears to be a well qualified candidate for this study. Guerrero is along the 
MAT, where the Cocos plate subducts beneath the North American Plate

(Figure 1). The convergence rate varies from $53 \mathrm{~mm} / \mathrm{yr}$ to $58 \mathrm{~mm} / \mathrm{yr}$ along the trench in direction N33ㄹ E [NUVEL1-A, DeMets et al., 1994]. No significant seismic energy has been released in the northwest seismic gap $\left(\sim 260^{\circ}\right.$ to $\left.258.8^{\circ} \mathrm{E}\right)$ since the rupture of the December $16,1911\left(M_{s}=7.8\right)$ earthquake [Ortiz et al., 2000]. The most recent large earthquakes in the southeast seismic gap $\left(\sim 261^{\circ}\right.$ to $\left.260^{\circ} \mathrm{E}\right)$ were in $1907\left(M_{s}=7.9\right)$ and $1957\left(M_{s}=7.8\right)$. These two segments are roughly within the area affected by aseismic transients, and covered by the Guerrero Global Positioning System (GPS) network. The first continuous GPS station in Guerrero was established at CAYA in January 1997. Permanent and campaign instrumentations were installed subsequently, and now consist of over 10 years of deformation record at some sites [Larson et al., 2004]. Locations of the permanent stations are shown in Figure 1. Two large aseismic transients (southward surface displacement of $\sim 2$ to $5 \mathrm{~cm}$ ), which lasted for several months in early 1998 and from October 2001 to April 2002, respectively, have been reported from the continuous measurements [Lowry et al., 2001; Kostoglodov et al., 2003]. Recently, one transient with a deformation size comparable to the 2001-2002 event was detected from March to December 2006 [Larson et al., 2007]. Complete GPS time series of the north-component displacement between 1996 and 2004 are shown in Figure 1 of Lowry [2006].

\section{Earthquake catalogs and determination of completeness magni- tude $M_{c}$}

The GCMT (Global Centroid Moment Tensor) and NEIC (National Earthquake Information Center) catalogs are searched for seismic events between 
1995 and 2006, within the area of latitude $16^{\circ}$ to $20^{\circ} \mathrm{N}$ and longitude $258^{\circ}$ to $262^{\circ} \mathrm{E}$, which covers the region affected by the major transients since 1996 , and where the permanent Guerrero GPS network is installed. Earthquake depth is limited to those less than $100 \mathrm{~km}$, to roughly include events only related to the shallow subduction process. The relocated Centennial catalog [Engdahl et al., 1998; Engdahl and Villaseñor, 2002] is also used for better constraints on the locations of particular earthquakes of interest, as will be discussed in Section 3.

Among all the events satisfying the above search criterions, the lowest magnitude in the GCMT catalog is $M_{w}=4.9$, and the NEIC catalog includes smaller events down to $m b=2.5$. However, the number of events at lower magnitudes may increase with time as an effect of improved seismic instrumentation detection capability. That influences our attempts to identify the natural variations of seismicity rate. Thus, it is necessary to define a completeness (cut-off) magnitude $M_{c}$, above which the catalog can be considered complete and appropriate for this study. There are basically two approaches in the literature to determine $M_{c}$. One is to calculate what the instruments should be able to detect, given their configuration, sensitivity, noise level and observations of which earthquakes particular instruments have or have not detected, following the procedures in Schorlemmer et al. [2006]. This is a very precise but complicated approach for the purpose of the present study. As a simple and generally robust approach, we use the maximum likelihood method $[A k i, 1965]$ to calculate the $b$ value for a wide range of $M_{c}$ :

$$
b=\frac{\log _{10}(e)}{\langle M\rangle-M_{c}}=\frac{0.4343}{\langle M\rangle-M_{c}}
$$

where $\langle M\rangle$ is the mean magnitude of all events equal or higher than the de- 
tection threshold $M_{c}$. For all the NEIC earthquakes between 1995 and 2006, with depths less than $100 \mathrm{~km}$, within the dashed-line box, $b$-value, with $98 \%$ error bars, versus $M_{c}$ is shown in Figure 2(a). $b$ initially increases with $M_{c}$ when $M_{c}$ is below the detectability threshold. When $M_{c}$ is high enough, $b$ becomes statistically constant (e.g., $b$ is roughly constant for different values of $M_{c}$ within the calculation error), and the catalog can be considered as complete. A completeness magnitude of $\sim 4.3$ can be roughly determined. In addition, the frequency-magnitude distributions, shown in Figure 2(b), also suggest a $M_{c}$ around the same value. We assume the drop in the number of events within each 0.1-magnitude bin is caused by the incomplete reporting of events in the NEIC catalog. Adding a 0.2 or 0.3 safe factor to $M_{c}$ inferred from the statistical analysis [K. Felzer, priv. commun.], we choose a completeness magnitude of $M_{c}=4.5$. It is also consistent with an average completeness threshold of 4.3 to 4.4 reported for the NEIC catalog in a majority of regions [http://earthquake.usgs.gov/regional/neic/neic_bulletins.php, 2000]. The Centennial catalog has a cut-off magnitude of 5.5 for earthquakes between 1964 and April 2002.

In Section 3, we present the seismicity variations between 1995 and 2006, showing the distribution of GCMT and NEIC events, the epicentral distance to trench versus time, and the seismicity rate in each four-year span, i.e., 1995-1998, 1999-2002 and 2003-2006. The earthquakes for periods including the three large transients are projected to a vertical cross-section along line $\mathrm{AB}$ (Figures 3,5 and 7), which is perpendicular to the trench. We use the subduction slab geometry, specifically, the thrust interface profile determined by Kostoglodov et al. [1996] using the seismicity data of the regional network in Guerrero. The slab profile is also used in the dislocation model of Kostoglodov 
et al. [2003] to fit the observed surface deformation in the 2001-2002 transient.

\section{Seismicity and transients, 1995-2006}

\section{$3.1 \quad 1995-1998$}

Figure 3(a) is the map view of the seismicity from GCMT (beachballs) and NEIC (gray dots) catalogs between 1995 and 1998. Figure 3(b) shows earthquakes between 1997 and 1998 in the dashed-line box projected to a vertical cross-section along $\mathrm{AB}$ (red line). For the same earthquake of interest, we plot the compressional quadrants of the GCMT beachball, the NEIC and Centennial (if available in that catalog) locations with the same color.

\subsubsection{Possible transient in 1996}

Before the first permanent GPS station was installed at CAYA in January 1997, survey measurements were conducted in March 1992, September 1995 and April 1996, along the coast and inland in Guerrero. For a complete description of campaign sites and operation epoches, see Larson et al. [2004]. Evidence of a moderate-size transient was found from the 1995 and 1996 survey records at ACAP (Acapulco). The north component of displacement relative to the North American Plate is $\sim 2 \mathrm{~cm}$ [Larson et al., 2004], almost one order of magnitude larger than the average horizontal surface deformation during the northern Cascadia aseismic transients [Dragert et al., 2001]. However, we need to be cautious on the identification of this transient based on the campaign data at a single station, as transient motions can also result from the 
instability of the monument, localized mass-wasting phenomena, or different conditions in campaign epoches. The possibility that the slow slip was triggered by the $M_{w}=7.3$, September 1995 Copala earthquake ("091405C" in Figure 3(a)), $100 \mathrm{~km}$ east of ACAP, cannot be ruled out.

Figure 4(a) shows the temporal variation of the epicentral distance to the trench of NEIC events greater than 4.2 in the dashed-line box between 1995 and 1998. Blue and red circles represent earthquakes with normal- and thrustfaulting focal mechanisms, respectively. The duration of the 1996 transient is poorly constrained due to limited measurements. We mark it roughly from November 1995 to February 1996, in Figure 4(a), based on the estimate by Larson et al. [2004]. Since the beginning of 1995, no earthquakes with magnitude higher than 4.5 were reported in either catalog until December 20, 1995, when a $M_{w}=5.3$ normal-faulting earthquake occurred near the border between Guerrero and Michoacán, with an epicentral distance of $\sim 170 \mathrm{~km}$ inland from the trench and a depth of $78 \mathrm{~km}$ (NEIC). A similar depth of 76 $\mathrm{km}$ is determined in GCMT. This extensional earthquake corresponded to the initiation of the possible 1996 transient, and occurred in the subducting slab. A thrust earthquake of $M_{w}=5.5$ occurred on April 23, 1996, shortly after the transient, given the estimated duration. While the GCMT centroid location of the April event lies on the trench, NEIC reports an epicenter $\sim 40 \mathrm{~km}$ inland from the trench, which is probably a more precise estimate using data from regional seismic network in Guerrero. Another cluster of thrust events was reported in middle July, with the largest magnitude of $M_{w}=6.6$. 


\subsubsection{Transient in 1998}

About 1 year after the first permanent GPS station was installed at CAYA, a transient motion, starting from early 1998, was observed and lasted for $\sim 5$ months. The reversed motion was later confirmed by displacement at an inland station POSW. Continuous measurements from the beginning of 1997 to late 2000 were used to model the aseismic deformation and suggest a total static displacement of $2 \mathrm{~mm}$ east, $26 \mathrm{~mm}$ south and $16 \mathrm{~mm}$ up during this transient [Lowry et al., 2001]. Along-strike propagation, a feature like that exhibited by the Cascadia transients [Dragert et al., 2001], is also implied based on the surface eastward deflection at the beginning and westward deflection at the end of the transient; a simple static slip patch cannot duplicate such a time-varying feature. The deflection signal is consistent with a NW to SE slip propagation motion, as also suggested by the seismicity variation associated with this transient.

During the transient slip period, an extensional earthquake of $M_{w}=5.9$ occurred on April 20, 1998, on the NW border between Guerrero and Michoacán, near the epicenter of the 1995 normal-faulting earthquake. GCMT, NEIC and Centennial locations of this April event are shown in Figure 3 by a beachball with blue compressional quadrants, blue dot and blue star, respectively. There is a significant discrepancy of more than $40 \mathrm{~km}$ between the GCMT and NEIC horizontal locations, and NEIC has better agreement with the relocated Centennial position. Earthquakes with magnitudes less than 4.5, shown as gray circles in Figure 4(a), near the extensional earthquake epicentral area were also reported preceding or at the early stage of the 1998 transient. Furthermore, a group of thrust-faulting earthquakes occurred near Acapulco in July 1998, immediately after the transient. It is clear from Figures 3 and 4 that 
the 1998 transient coincided with an extensional earthquake in the subducting slab at NW Guerrero and was followed by a cluster of shallower thrust earthquakes close to the trench near Acapulco, suggesting a NW to SE slow slip propagation and up-dip stress transfer.

Figure 4(b) shows the number of seismic events, above the completeness magnitude 4.5 (black bars) and between 4.2 and 4.5 (gray bars), per 10 days for the examined 4-year period. High seismic rate is generally observed in the temporal vicinity of the transient slip events.

\section{$3.2 \quad 1999-2002$}

Figure 5(a) is the map view of the seismicity from GCMT and NEIC catalogs between 1999 and 2002. Figure 5(b) shows the earthquakes between 2001 and 2002 within the dashed-line box projected to the vertical cross-section along $\mathrm{AB}$.

\subsubsection{Large transient in 2001-2002}

From early 1999 to late 2001, GPS measurements vaguely suggest three small aseismic transients with the north-component of displacement less than $2 \mathrm{~mm}$, at least an order of magnitude smaller than that of the 1998 transient [Lowry, 2006]. Seismicity during the same period is relatively sparse, as shown in Figure 6.

The Guerrero region became seismically more active since late 2001, signifying the beginning of a large transient. Aseismic deformation is clearly visible on the time series of all permanent GPS stations then operating [Kostoglodov et 
al., 2003]. The reversed motion was first detected at stations ACAP, CAYA, IGUA and YAIG, near the border of the NW and SE seismic gaps, then about two months later, at a northwest station ZIHP and southeast stations PINO, OAXA ( $120 \mathrm{~km}$ northeast of PINO, not shown in Figure 1$)$. The temporal delay in the transient motion onsets at different stations suggests a bilateral propagation at a speed of about 6-9 km/day [Kostoglodov et al., 2003], similar to the speed inferred for the northern Cascadia and southwest Japan short-term slow slip events. Anomalous surface deformation was observed from October 2001 to April 2002 over an area of more than $\sim 550 \times 250 \mathrm{~km}^{2}$, resulting in an equivalent moment magnitude of $\sim 7.5$.

A cluster of earthquakes relatively far inland from the trench coincided with the beginning of the transient. Two of them ("100801B" and "102901B" in Figure 5) are normal-faulting events with $M_{w}=5.8$ and 5.0. While the GCMT and NEIC catalogs are ambiguous in the depths of the two extensional earthquakes, a study reported in an abstract by Pacheco et al. [2002] suggests the October 8, 2001 Coyuca earthquake occurred at a shallow depth of 8 $\mathrm{km}$ and is thus a crustal event. GCMT and NEIC report depths at 10 and $15 \mathrm{~km}$, respectively, and are suspected to be fixed depths in both catalogs. As shown in Figure 5(b), the GCMT location of "100801B" is shifted by 30-40 km inland from its NEIC epicenter (blue dot). The Centennial cata$\log$ (blue star) and records from the Guerrero Accelerograph Network stations [http://www.seismo.unr.edu/Guerrero/] also suggest epicenters close to the NEIC location. The normal-faulting mechanism might be explained by the shallow extensional stresses left in the wake of indentation of the upper plate by the locally steepened section of the slab near $80 \mathrm{~km}$ from the trench. 265 The possibility that event "100801B" might have been triggered by the tran- 
sient is also mentioned by Kostoglodov et al. [2003], although their discussion would seem to require an offshore nucleation of the transient slip. Nevertheless, the epicenters of the two October earthquakes are approximately along the same trench-normal line inland from stations CAYA, ACAP, where the transient episode started. This spatial-temporal correlation provides evidence that stressing from the nearby seismicity may have triggered the transient or had a common origin with it. The seismic rates became higher during the transient; the October 8 Coyuca earthquake produced a large number of aftershocks $(>300)$ that lasted $\sim 6$ months, overlapping the duration of the transient [Kostoglodov et al., 2003]. We also note that toward the end of the transient, in middle April 2002, several thrust-faulting earthquakes occurred close to the trench, more than $100 \mathrm{~km}$ west of stations CAYA, ACAP. This is also consistent with the bilateral propagation of the slow slip event. The largest magnitude of the thrust events is $M_{w}=6.7$ ("041802B" in Figure 5). Although, GCMT and NEIC horizontal locations have a $\sim 30 \mathrm{~km}$ discrepancy in the trench-normal distance, the along-strike locations are relatively well resolved, thus wouldn't affect the consistency with the slow slip propagation direction.

\section{$3.32003-2006$}

Figure 7(a) is the map view of the seismicity from GCMT and NEIC catalogs between 2003 and 2006. Figure 7(b) shows the earthquakes between 2005 and 2006 within the dashed-line box projected to the vertical cross-section along $\mathrm{AB}$. 


\subsubsection{Two possible small transients in 2003 and 2004}

Lowry [2006] also inferred a small aseismic transient from late 2002 to early 2003, as marked on Figure 6 and continued on Figure 8. The deformation signal is most prominent at coastal stations ZIHP and CAYA, which are in the epicentral area of many small earthquakes during that period, suggesting a casual relation between the seismicity and transient. We cannot rule out the possibility that it is an aftermath of the large transient in 2001-2002, as most of the seismicity in late 2002 and early 2003 are close the the trench and many have thrust-faulting focal mechanisms.

An even smaller transient was inferred to have occurred in early 2004 [Lowry, 2006], as marked in Figure 8. We do not discuss that in detail, due to the little constraint on deformation. Similarly, seismicity rate was high during and after this possible transient, with a majority of earthquakes close to the trench.

\subsubsection{Large transient in 2006}

The most recently detected large transient in the Guerrero region started around March 2006, and the GPS signal began to return to the normal trend at some stations in late September while extending into December at others [Larson et al., 2007]. The size of this transient is comparable to that in 20012002; the total horizontal displacement at CAYA is about $6 \mathrm{~cm}$. The reversed motion was continuously observed at all permanent GPS stations, except ZIHP where only a net displacement before and after the transient is obtained due to technical problems. Larson et al. [2007] modeled the deformation with four patches of rectangular fault planes, and found the east-component of the slip anomaly can be divided into two stages. In the first stage, from February to 
June 2006, stations (CAYA, COYU, ACAP, ACYA and CPDP) near the coast experienced a faster eastward movement. That was followed, in the second stage, by a westward motion from May to the end of this transient episode. On the contrary, inland stations (MEZC, IGUA and YAIG) moved faster toward the west in the first stage and continued to move westward but with gradually decreasing slip rates.

The 2006 large transient was preceded by a cluster of earthquakes far inland on the NW border of Guerrero, in the same epicentral area of the extensional earthquakes in 1996 and 1998. The earliest among the cluster of GCMT events was a $M_{w}=4.9$, normal-faulting earthquake on December 14, 2005 ("121405A" in Figure 7, colored blue), about two months before the transient. On February 20, 2006, shortly before the transient signal could be detected by GPS, a $M_{w}=5.2$ event ("022006A", colored green) occurred at roughly $150 \mathrm{~km}$ (NEIC) inland from the trench. One month later, another normal-faulting event with a similar magnitude was reported in GCMT with its centroid location slightly NW out of the dashed-line box ("032006A"). More earthquakes with large distances to the trench were observed during the transient; the largest with a $M_{w}=6.0$ on August 11, 2006 ("081106A", colored orange). All of the three normal-faulting earthquakes in February, March and August 2006 are located at depths $\sim 60 \mathrm{~km}$ or deeper thus in the subducting slab. The GCMT and NEIC horizontal locations agree relatively well with each other, except for event "022006A". Toward the end of the transient, the seismicity cluster seemed to migrate closer to the trench. Although all events are too small to have GCMT solutions, their locations suggest a shallow thrust focal mechanism. We also plot in Figure 7 a recent $M_{w}=5.9$ thrust earthquake on April 13, 2007 ("041307A"), which lies southeast from the ex- 
tensional earthquakes cluster before and during the transient, and is much closer to the trench. Although the GCMT solution suggests the thrust fault plane activated during event "041307A" inclines either toward the ocean or toward the continent at a steeper angle than the subducting slab, the spatial evolution of seismicity cluster is consistent with a northwest toward southeast aseismic slip migration implied from the transient duration offsets at different GPS stations [Larson et al., 2007].

\section{Conclusion and discussion}

Recent observations of aseismic deformation transients and sometimes associated deep non-volcanic tremors in the circum-Pacific subduction zones pose significant questions as to their origin, and also relative to existing concepts of interseismic loading of the locked seismogenic regions. Stressing in the up-dip seismogenic zone is increased episodically due to down-dip transient slips, and 2 it can be made more prone to failure in a large thrust earthquake. Thus, it is important for seismic hazard assessment to search and identify patterns of spatiotemporal seismicity variation associated with transients. We rejuvenate the suggestions made by Dmowska et al. [1988], which could not be linked to a convincing mechanism at that time, on possible communication between extensional seismicity clusters down-dip in the slab, and later thrust clusters in the shallow seismogenic zone, along the Middle American Trench off Mexico. The pattern seems to continue in the recent seismicity along other region of MAT (Guerrero) that we have studied here.

We searched the GCMT and NEIC catalogs for earthquakes in a twelve-year period (1995-2006) in the area affected by the aseismic transients in Guer- 
rero, Mexico. The seismicity variation patterns are identified to be spatialtemporally associated with the transients observed by the Guerrero GPS network since 1996. Three large transients in 1998, 2001-2002 and 2006 are all correlated with high seismic rates in the studied area. In particular, we found that the initiation of the transients occurs in association with a cluster of extensional earthquakes relatively far inland from the trench, in the subducting slab or the overlying crust, and may be followed by a cluster of shallow earthquakes close to the trench, among which many have thrust-faulting mechanisms. In some cases, such as the transient in 2001-2002, both types of activity are found bracketing the transient period. The beginning of the 2006 transient coincided with two normal-faulting earthquakes in February and March, 2006, near the northwest border of Guerrero. Toward the end of the transient, the NEIC catalog shows the seismicity cluster moved closer to the trench, implying hypocenters up-dip in the seismogenic zone.

The assembled evidence suggests that aseismic deformation transients may serve as a mechanism of stress communication between distant regions, e.g., down-dip and up-dip, in subduction zones. The Guerrero transients seem to be initiated by earthquakes far inland from the trench, in subducting slab or the continental crust, or to have a common cause of that activity. They transfer stresses to the locked shallow part in a manner which sometimes results in thrust earthquakes there. That conjecture has been taken into account in the numerical modeling of subduction earthquakes and aseismic transients using the rate and state-dependent friction [Liu and Rice, 2007]. When a moderate, step-like stress perturbation, e.g., from a nearby earthquake, is applied to the thrust interface, sequential aseismic transients can be resulted, and the timing of the next large thrust earthquake is affected by three factors, namely, when, 
where and how large is the stress perturbation.

The discovery of aseismic deformation transients is an important development in our knowledge of the seismic cycle along major plate boundaries. It poses significant puzzles and changes the way we should think about the loading of seismogenic zones. Such transients contribute episodic steps in loading to the thrust interface. Their improved understanding seems likely, based on observations for the MAT and on theory, to increase the predictability of earthquakes.

\section{Acknowledgments}

This work was supported at Harvard by NSF-EAR award 0510196 and USGS grants 06HQGR0047 and 07HQGR0057, and at the University of Colorado by NSF-EAR award 0609646. We thank Karen Felzer for discussion on the catalog completeness magnitude, Renata Dmowska and Meredith Nettles for comments on various aspects of the study, Vladimir Kostoglodov and Jose Antonio Santiago (UNAM) for support of the GPS network in Guerrero, and Göran Ekström and Roland Bürgmann for comments which helped to improve the original presentation.

\section{References}

Aki, K., Maximum likelihood estimate of $b$ in the formula $\log N=a-b M$ and its confidence limits (1965), Bull. Earthquake Res. Inst., 43, 237-239.

DeMets, C., R. G. Gordon, D. F. Argus, and S. Stein (1994), Effect of recent 
revisions to the geomagnetic reversal time scale on estimates of current plate motions, Geophys. Res. Lett., $21(20)$, 2191-2194.

Dragert, H., K. Wang, and T. S. James (2001), A silent slip event on the deeper Cascadia subduction interface, Science, 292(5521), 1525-1528.

Dmowska, R., J. R. Rice, L. C. Lovison, and D. Josell (1988), Stress transfer and seismic phenomena in coupled subduction zones during the earthquake cycle, J. Geophys. Res., 93(B7), 7869-7884.

Douglas, A., J. Beavan, L. Wallace, and J. Townend (2005), Slow slip on the northern Hikurangi suduction interface, New Zealand, Geophys. Res. Lett., 32(L16305), doi:10.1029/2005GL023607.

Engdahl, E. R., R. van der Hilst, and R. Buland (1998), Global teleseismic earthquake relocation with improved travel times and procedures for depth determination, Bull. Seism. Soc. Am., 88, 722-743.

Engdahl, E. R., and A. Villaseñor (2002), Global seismicity: 1900-1999, in W. H. K. Lee, H. Kanamori, P. C. Jennings, and C. Kisslinger (editors), International Handbook of Earthquake and Engineering Seismology, Part A, Chapter 41, pp. 665-690, Academic Press.

Hirose, H., K. Hirahara, F. Kimata, N. Fujii, and S. Miyazaki (1999), A slow thrust slip event following the two 1996 Hyuganada eartqhuakes beneath the Bungo Channel, southwest Japan, Geophys. Res. Lett., 26(21), 3237-3240.

Hirose, H., and K. Obara (2005), Repeating short- and long-term slow slip events with deept tremor activity arouond the Bungo channel region, southwest Japan, Earth Planets Space, 57(10), 961-972.

Kao, H., S-J. Shan, H. Dragert, G. Rogers, J. F. Cassidy, and K. Ramachandran (2005), A wide depth distribution of seismic tremors along the northern Cascadia margin, Nature, 436(7052), 841-844.

Kostoglodov, V., W. Bandy, J. Dominguez, and M. Mena (1996), Gravity 
and seismicity over the Guerrero seismic gap, Geophys. Res. Lett., 23(23), $3385-3388$.

Kostoglodov, V., S. K. Singh, J. A. Santiago, K. M. Larson, A. R. Lowry, and R. Bilham (2003), A large silent earthquake in the Guerrero seismic gap, Mexico, Geophys. Res. Lett., 30(15), 1807, doi:10.1029/2003GL017219.

Larson, K. M., A. R. Lowry, V. Kostoglodov, W. Hutton, O. Sánchez, K. Hudnut, and G. Suárez (2004), Crustal deformation measurements in Guerrero, Mexico, J. Geophys. Res., 109 (B04409), doi:10.1029/2003JB002843.

Larson, K. M., V. Kostoglodov, S. Miyazaki, and J. A. Santiago (2007), The 2006 aseismic slow slip event in Guerrero, Mexico: New results from GPS, Geophys. Res. Lett., 34, L13309, doi:10.1029/2007GL029912.

Liu, Y., and J. R. Rice (2005), Aseismic slip transients emerge spontaneously in three-dimensional rate and state modeling of subduction earthquake sequences, J. Geophys. Res., 110(B08307), doi:10.1029/2004JB003424.

Liu, Y., and J. R. Rice (2007), Spontaneous and triggered deformation transients in a subduction fault model, J. Geophys. Res., in press.

Lowry, A. R., K. M. Larson, V. Kostoglodov, and R. Bilham (2001), Transient fault slip in Guerrero, southern Mexico, Geophys. Res. Lett., 28(19), 37533756.

Lowry, A. R. (2006), Resonant slow fault slip in subduction zones forced by climatic load stress, Nature, 442(7104), 802-805.

Manea, V. C., M. Manea, V. Kostoglodov, C. A. Currie, and G. Sewell (2004), Thermal structure, coupling and metamorphism in the Mexican subduction zone beneath Guerrero, Geophys. J. Int., 158(2), 775-784.

Mazzotti, S., and J. Adams (2004), Variability of near-term probability for the next great earthquake on the Cascadia subduction zone, Bull. Seismol. 
Soc. Amer., 94 (5), 1954-1959.

Meltzner, A. J., K. Sieh, R. Briggs, H.-W. Chiang, C.-C. Shen, and B. W. Suwargadi (2007), Coseismic, postseismic, and interseismic deformation at the boundary of the 2004 and 2005 megathrust ruptures: Insights from coral microtolls, Seism. Res. Lett., 78(2), 300.

McCausland, W., S. Malone, and D. Johnson (2005), Temporal and spatial occurrence of deep non-volcanic tremor: From Washington to northern California, Geophys. Res. Lett., 32(L24311), doi:10.1029/2005GL024349.

Murray, J. R., and P. Segall (2005), Spatiotemporal evolution of a transient slip event on the San Andreas fault near Parkfield, California, J. Geophys. Res., 110 (B09407), doi:10.1029/2005JB003651.

Natawidjaja, D. H., K. Sieh, S. N. Ward, H. Cheng, R. L. Edwards, J. Galetzka, and B. W. Suwargadi (2004), Paleogeodetic records of seismic and aseismic subduction from central Sumatran microatolls, Indonesia, J. Geophys. Res., 109 (B04306), doi:10.1029/2003JB002398.

Natawidjaja, D., K. Sieh, J. Galetzka, B. Suwargadi, H. Cheng, and R. L. Edwards (2007), Interseismic deformation above the Sunda megathrust recorded in coral microatolls of the Mentawai islands, West Sumatra, J. Geophys. Res., 112(B02404), doi:10.1029/2006JB004450.

Ohta, Y., J. T. Freymueller, S. Hreinsdottir, and H. Suito (2006), A large slow slip event and the depth of the seismogenic zone in the south central Alaska suduction zone, Earth Planet Sci. Lett., 247(1-2), 108-116.

Ortiz, M., S. K. Singh, V. Kostoglodov, and J. Pacheco (2000), Source areas of the Acapulco-San Marcos, Mexico earthquakes of $1962\left(M_{w}=7.1,7.0\right)$ and $1957\left(M_{w}=7.7\right)$, as constrained by tsunami and uplift records, Geofís. Int., 39, 337-348.

Ozawa, S., M. Murakami, M. Kaidzu, T. Tada, T. Sagiya, Y. Hatanaka, H. 
Yarai, and T. Nishimura (2002), Detection and monitoring of ongoing aseismic slip in the Tokai region, central Japan, Science, 298(5595), 1009-1012.

Ozawa, S., M. Murakami, M. Kaidzu, and Y. Hatanaka (2005), Transient crustal deformation in Tokai region, central Japan, until May 2004, Earth. Planets. Space, 57(10), 909-915.

Pacheco, J. F., A. Iglesias, and S. K. Singh, The 8 October Coyuca, Guerrero, Mexico earthquake (Mw 5.9): A normal fault in the expected compressional environment (2002), Seism. Res. Lett., 73(2), 263.

Rogers, G., and H. Dragert (2003), Episodic tremor and slip on the Cascadia subduction zone: The chatter of silent slip, Science, 300 (5627), 1942-1943.

Segall, P., E. K. Desmarais, D. Shelly, A. Miklius, and P. Cervelli (2006), Earthquakes triggered by silent slip events on Kilauea volcano, Hawaii, $\mathrm{Na}$ ture, 442(7098), 71-74.

Schorlemmer, D., J. Woessner, and C. Bachmann (2006), Probabilistic estimates of monitoring completeness of seismic networks, 100th Anniversary Earthquake Conference.

Shelly, D. R., G. C. Beroza, S. Ide, and S. Nakamula (2006), Low-frequency earthquakes in Shikoku, Japan, and their relationship to episodic tremors and slip, Nature, 442(7099), 188-191.

Szeliga, W., T. I. Melbourne, M. M. Miller, and V. M. Santillan (2004), Southern Cascadia episodic slow earthquakes, Geophys. Res. Lett., 31(L16602), doi:10.1029/2004GL020824.

Wallace, L. M., and J. Beavan (2006), A large slow slip event on the central Hikurangi subduction interface beneath the Manawatu region, North Island, New Zealand, Geophys. Res. Lett., 33(L11301), doi:10.1029/2006GL026009. Yoshida, A., K. Hososno, T. Tsukakoshi, A. Kobayashi, H. Takayama, and S. Wiemer (2006), Change in seismic activity in the Tokai region related 
to weakening and strengthening of the interplate coupling, Tectonophysics,

$518 \quad 417,17-31$. 


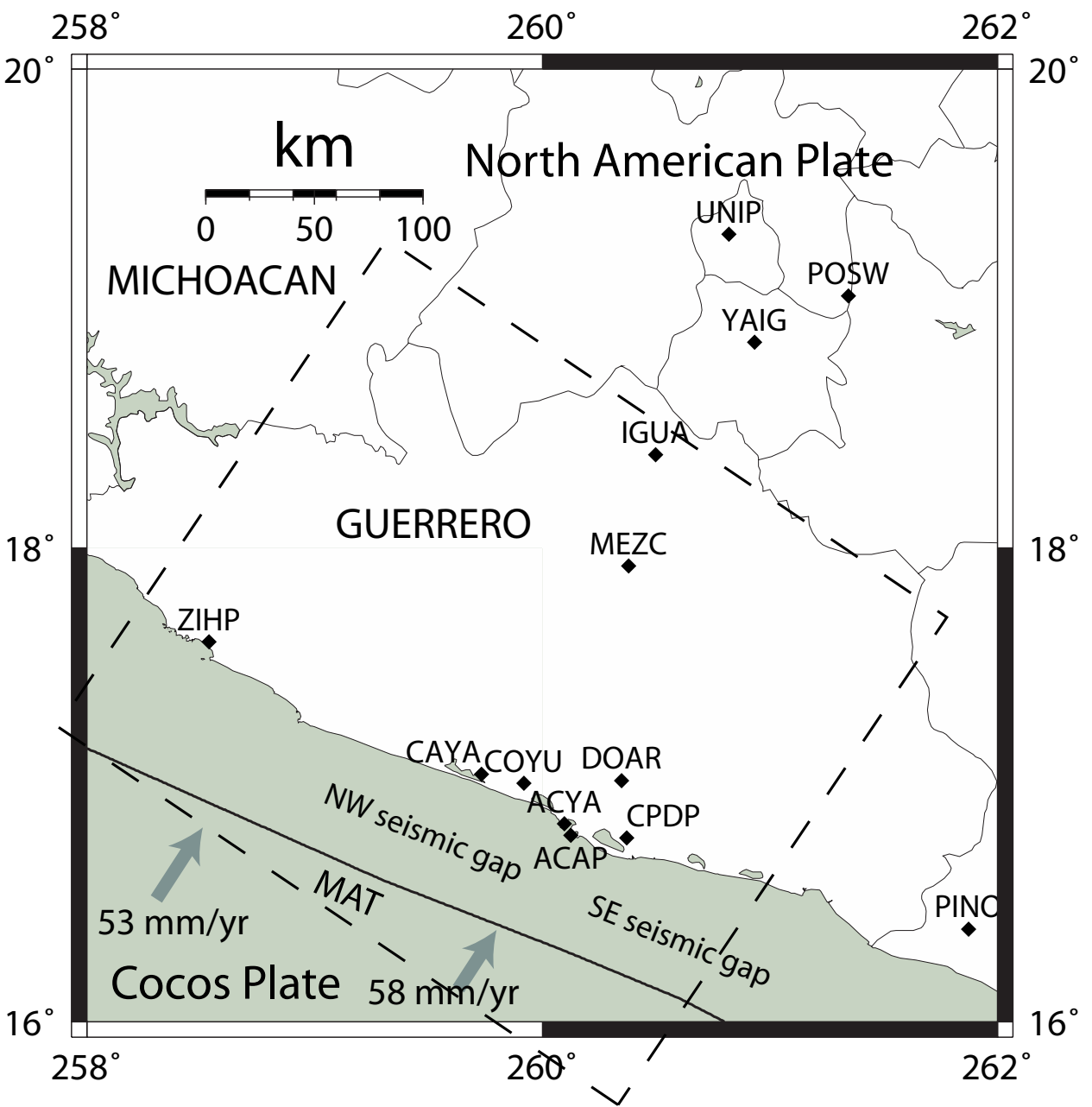

Fig. 1. Tectonic setting of the Guerrero, Mexico, region. Middle American Trench (MAT) defines the plate boundary between the Cocos and North American Plates. Bold arrows indicated the direction and magnitude of subduction, based on NUVEL1-A [DeMets et al., 1994]. Black diamonds show the locations of permanent GPS stations. Dashed-line box is along the subduction direction and surrounds the region where most of the Guerrero permanent GPS stations are installed and mainly affected by aseismic transients, and thus the studied area in this paper. 

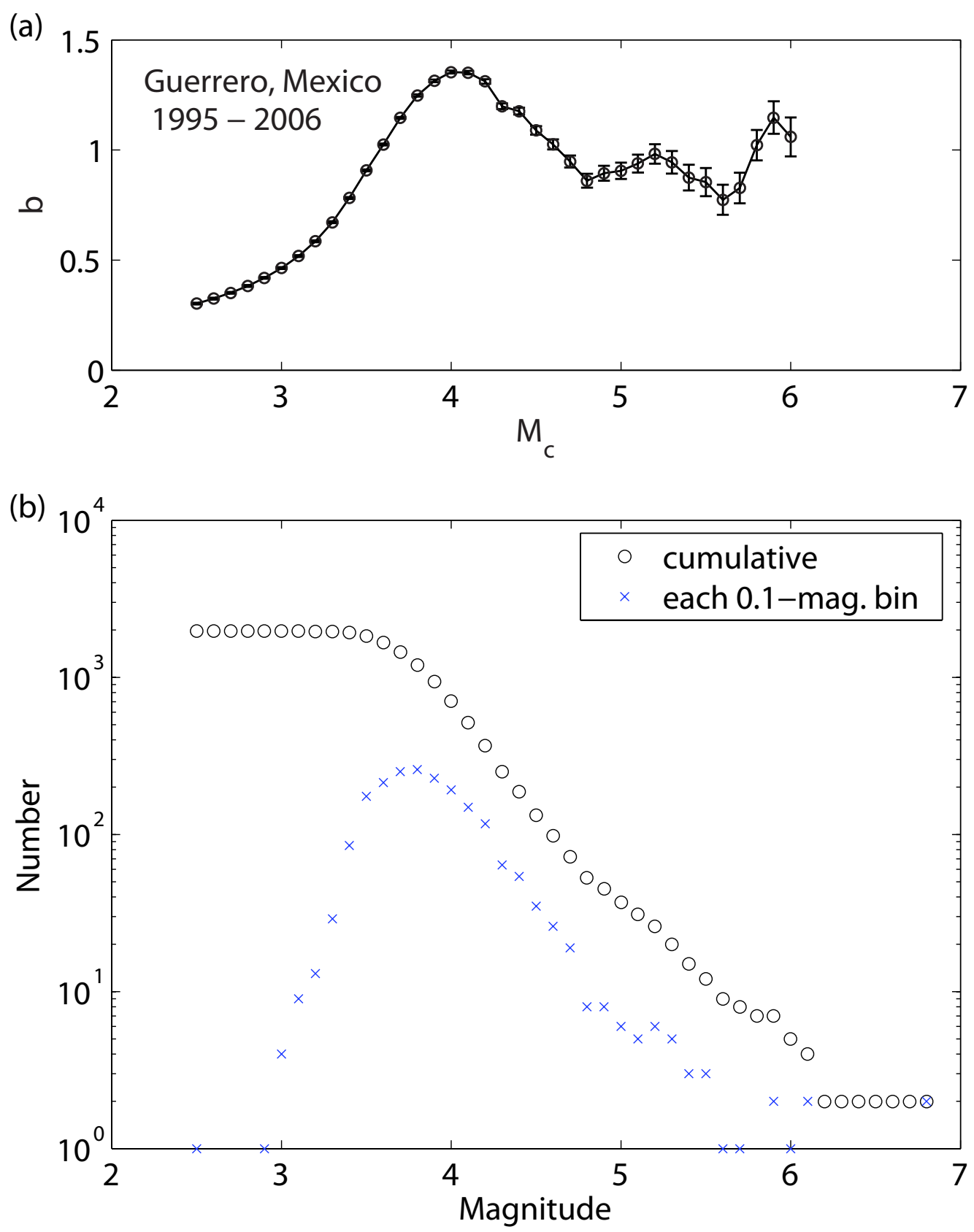

Fig. 2. (a) Calculated $b$-value versus completeness magnitude $M_{c}$ for all NEIC events, 1995-2006, depth less than $100 \mathrm{~km}$, within the dashed-line box shown in Figure 1. $98 \%$ error bars are shown on $b$. As $M_{c}$ increases, the number of analyzed events decreases, and the errors on $b$ becomes larger. $b$ becomes statistically constant for $M_{c} \geq 4.5$. (b) Number of events: cumulative (circle) and within each 0.1-magnitude bin (cross), for the same data set. Decrease of seismic activity for magnitude lower than $\sim 3.8$ is assumed to be due to the incomplete report of the NEIC catalog. A completeness (cut-off) magnitude of $M_{c}=4.5$ is used for subsequent analysis. 
Fig. 3. (a) Map view of seismicity in the Guerrero region, 1995-1998. Beachballs show the centroid locations and focal mechanisms of GCMT events. Labels on top are in order "Month/Day/Year/Event of that day". Gray dots show the epicenters of NEIC events larger than the completeness magnitude $M_{c}=4.5$. Dot size is proportional to event magnitude. GCMT and NEIC epicenters sometimes deviate by tens of km. NEIC events within the dashed-line box are used in the seismicity analysis. For reference, black diamonds represent locations of permanent GPS stations. (b) Seismicity, 1997-1998, within the dashed-line box projected to a vertical cross-section along AB (red line). Subduction thrust interface is adopted from Kostoglodov et al. [1996; 2003] and Manea et al. [2004]. The blue dot and beachball with blue compressional quadrants are NEIC and GCMT locations of the extensional earthquake "042098B", respectively. Blue star represents its position from the relocated Centennial catalog [Engdahl et al., 1998; Engdahl and Villaseñor, 2002]. 
(a)

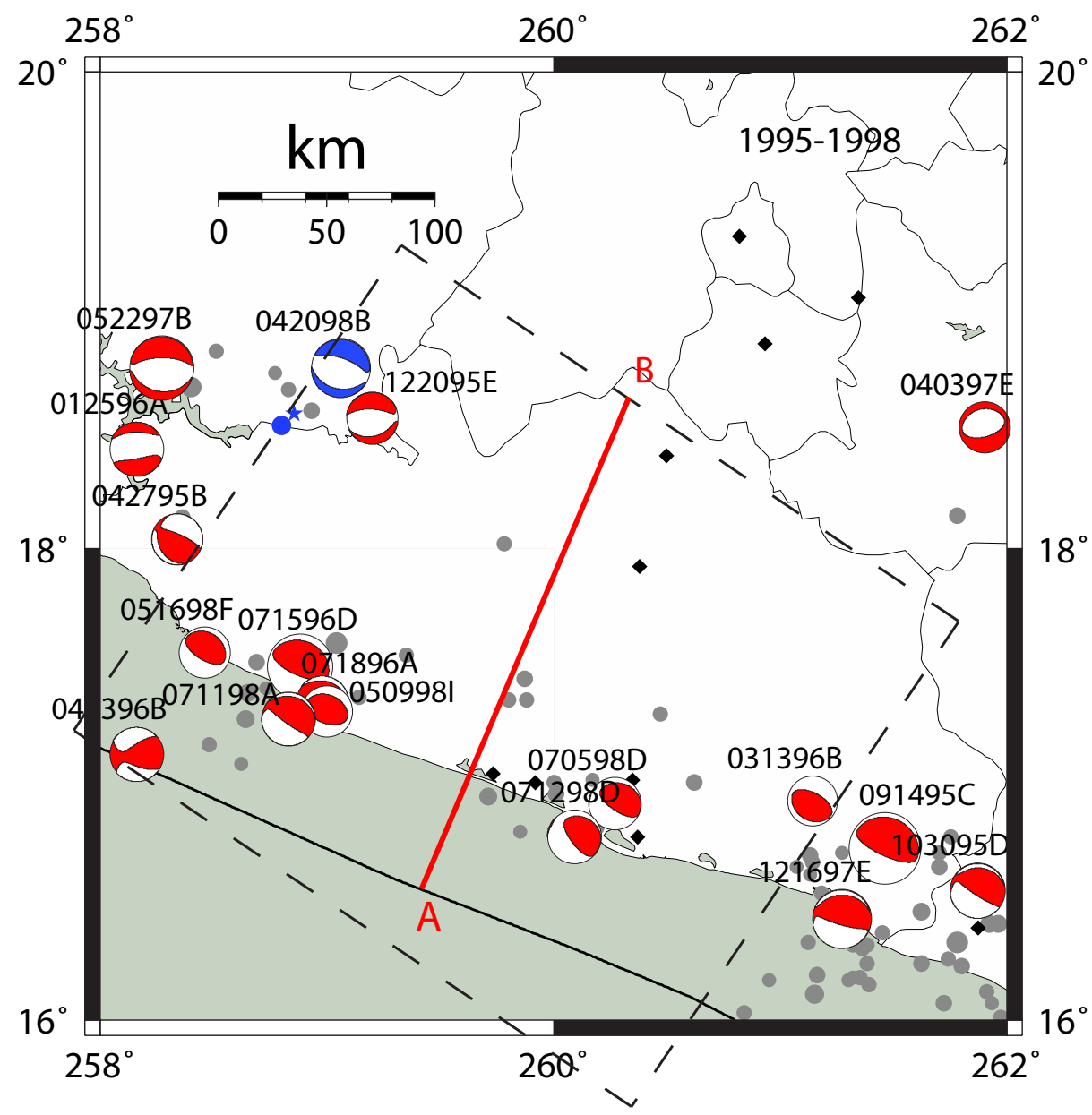

(b)

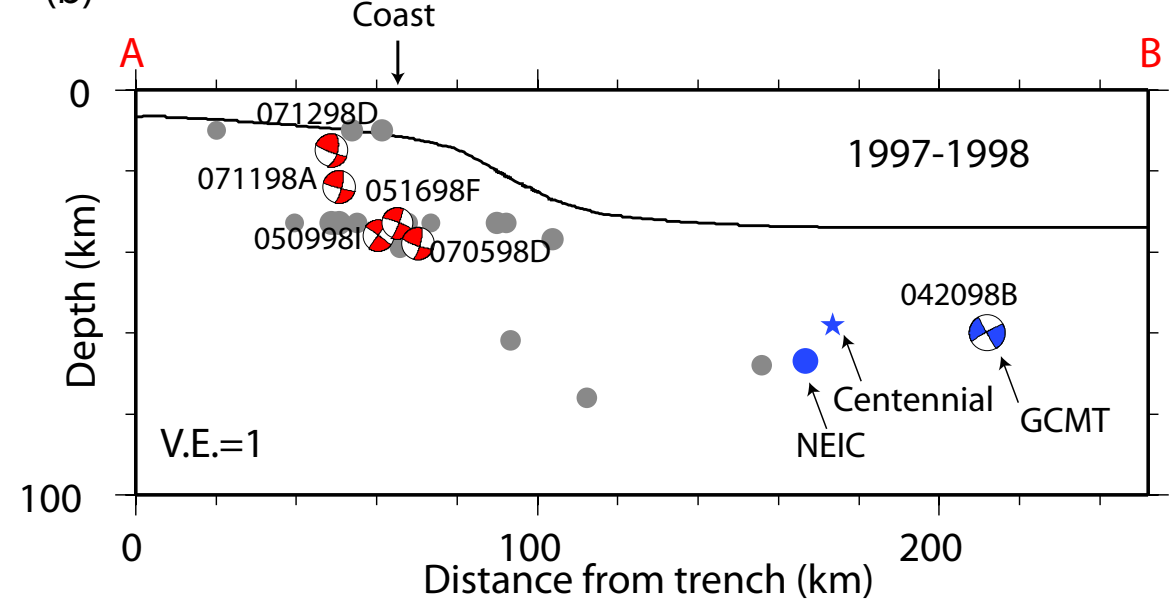



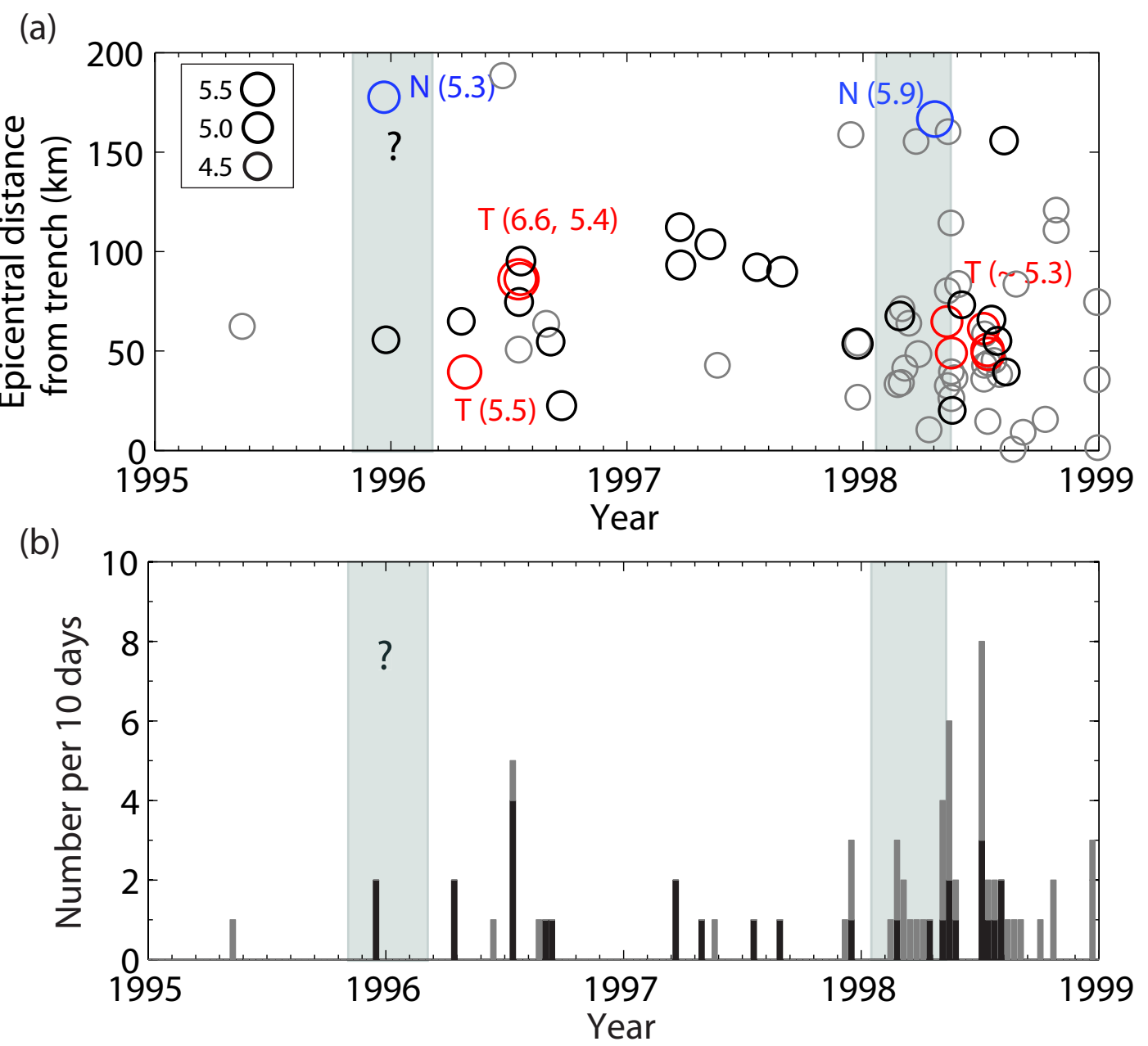

Fig. 4. (a) Spatial-temporal variation of NEIC events with magnitude greater than 4.2, within the dashed-line box, 1995-1998. Circle size is proportional to event magnitude. Blue and red circles are NEIC events that have GCMT solutions; blue: normal-faulting $(\mathrm{N})$, red: thrust-faulting $(\mathrm{T})$. Numbers in the parenthesis are moment magnitudes by GCMT. Only an average number is marked for a cluster of earthquakes, e.g., " $\mathrm{T}(\sim 5.3)$ " for the five thrust-faulting earthquakes after the 1998 transient. Gray circles represent events below $M_{c}=4.5$, but greater than 4.2 . (b) Number of earthquakes in every 10 days, 1995-1998. Black bars show numbers of events greater than $M_{c}=4.5$. Gray bars show numbers of events between 4.2 and 4.5. Two light gray strips approximately mark the durations of aseismic transients in, possibly, 1996, and 1998. 
(a)

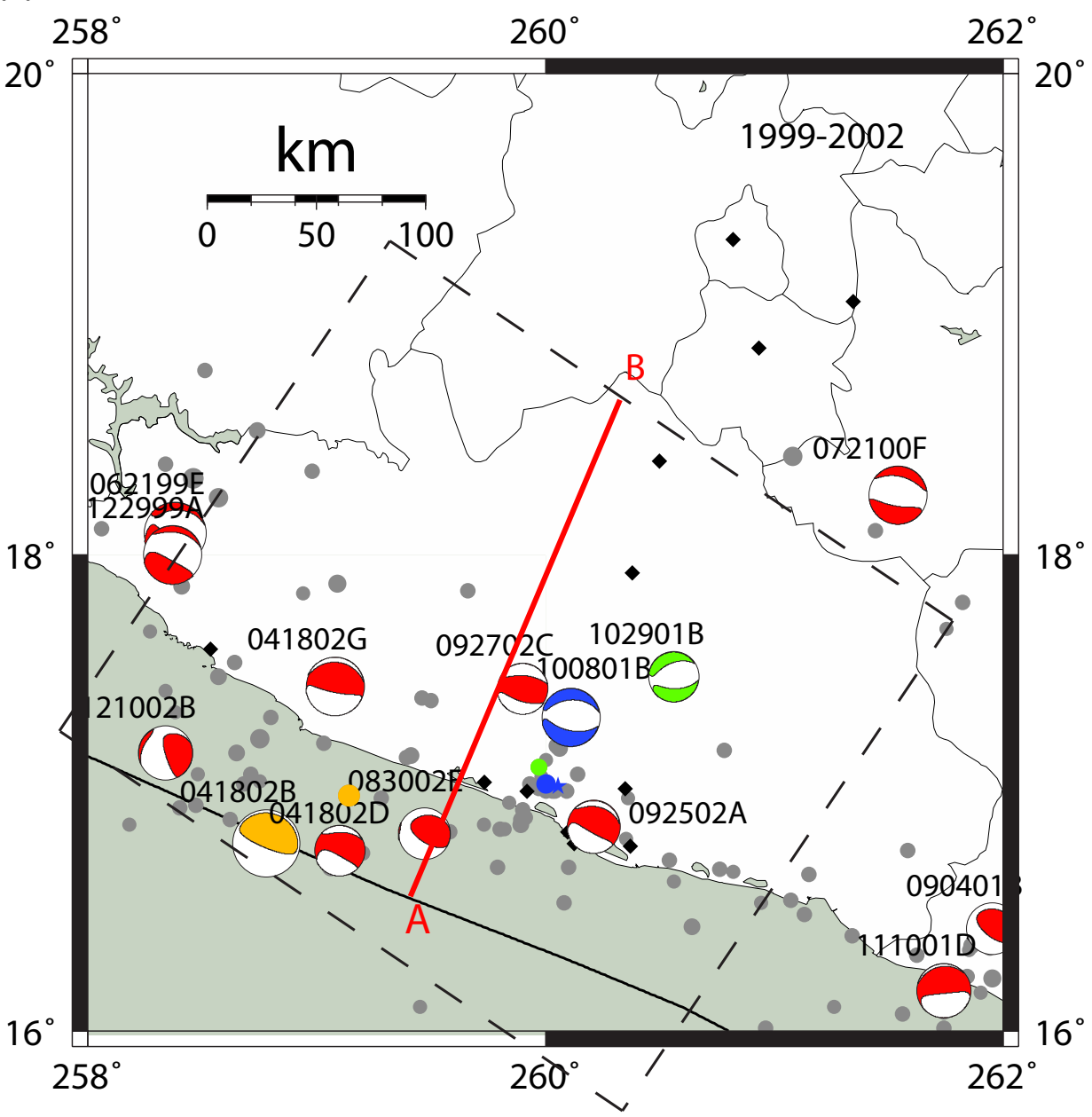

(b)

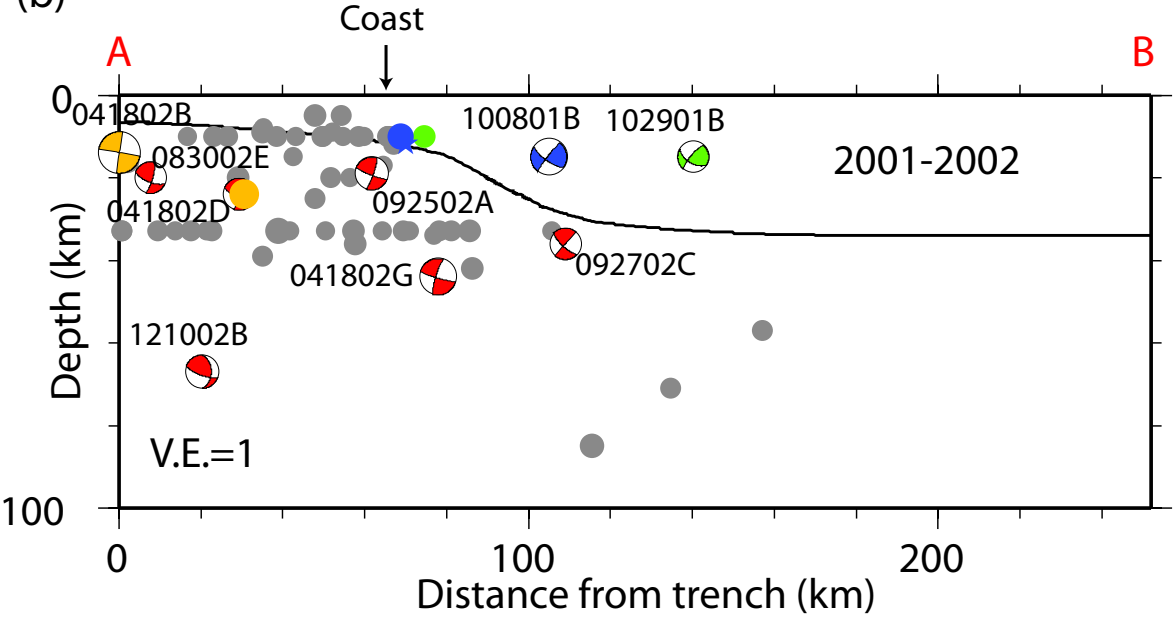

Fig. 5. (a) Map view of seismicity in Guerrero, 1999-2002. Extensional earthquakes "100801B" and "102901B" are colored in blue and green, respectively. Thrust event "041802B" is colored in orange. NEIC and Centennial locations of "100801B", represented by blue dot and star, almost overlap. (b) Seismicity, 2001-2002, within the dashed-line box projected to a vertical crass-section along AB. Legends are the same as in Figure 3. 

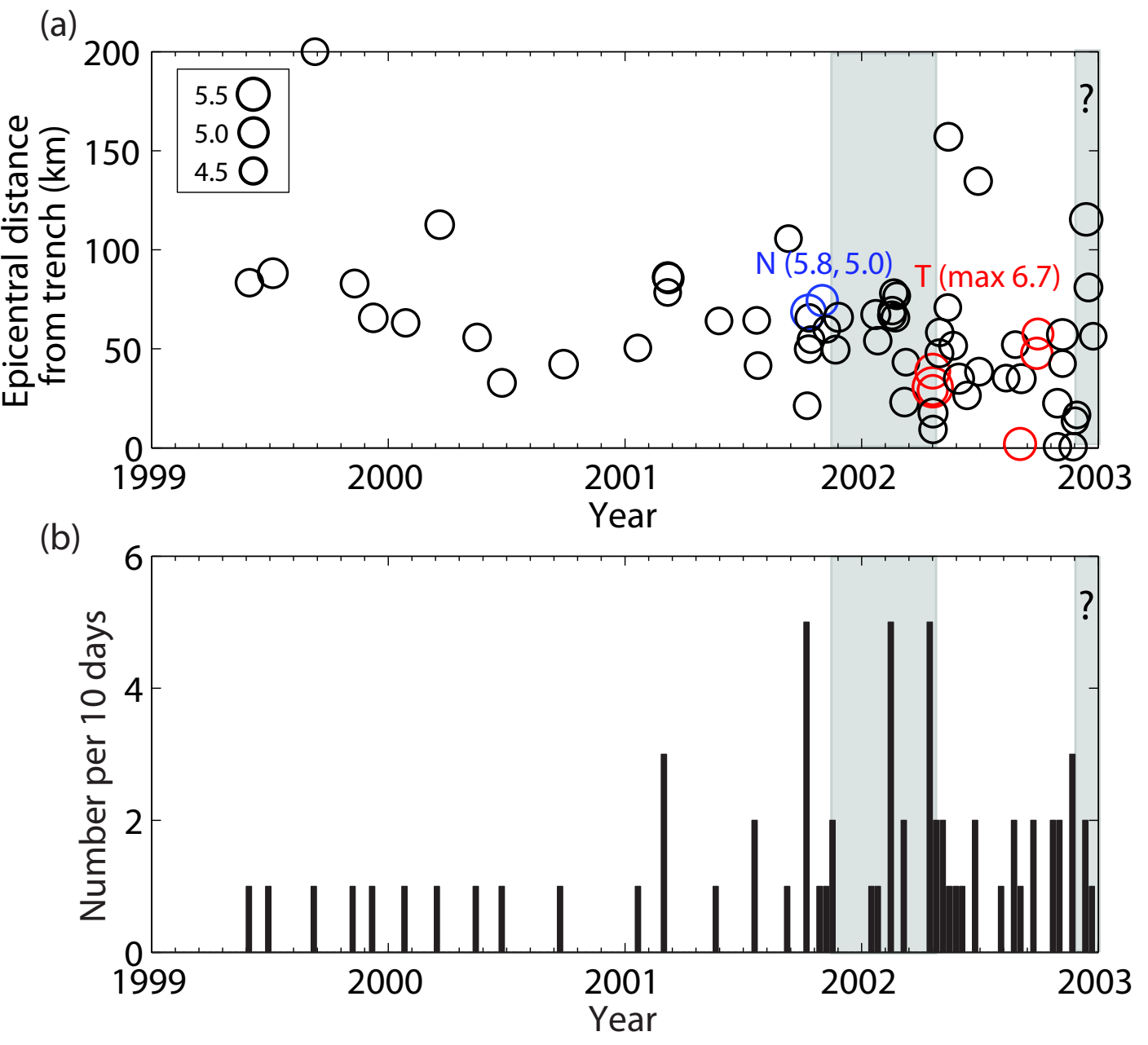

Fig. 6. (a) Epicentral distance from trench and (b) seismicity rate, 1999-2002. Symbol representations are the same as in Figure 4. NEIC events above the completeness magnitude $M_{c}=4.5$ are shown here. "T ( $\left.\max 6.7\right)$ " represents the largest moment magnitude among the thrust-faulting earthquakes (red circles) following the 2001-2002 transient is 6.7. The transient marked from late 2002 continues on Figure 8. 
(a)

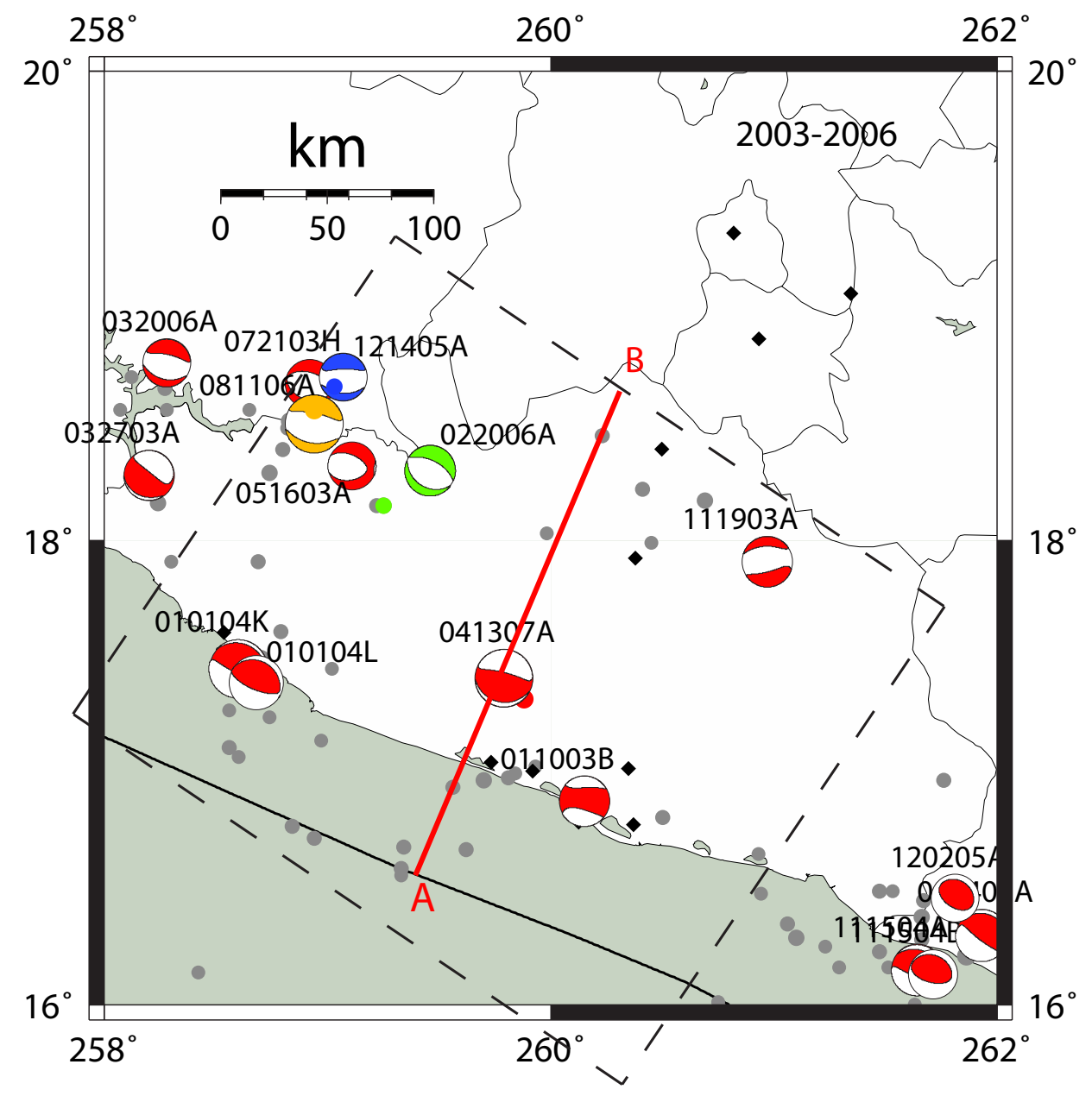

(b)

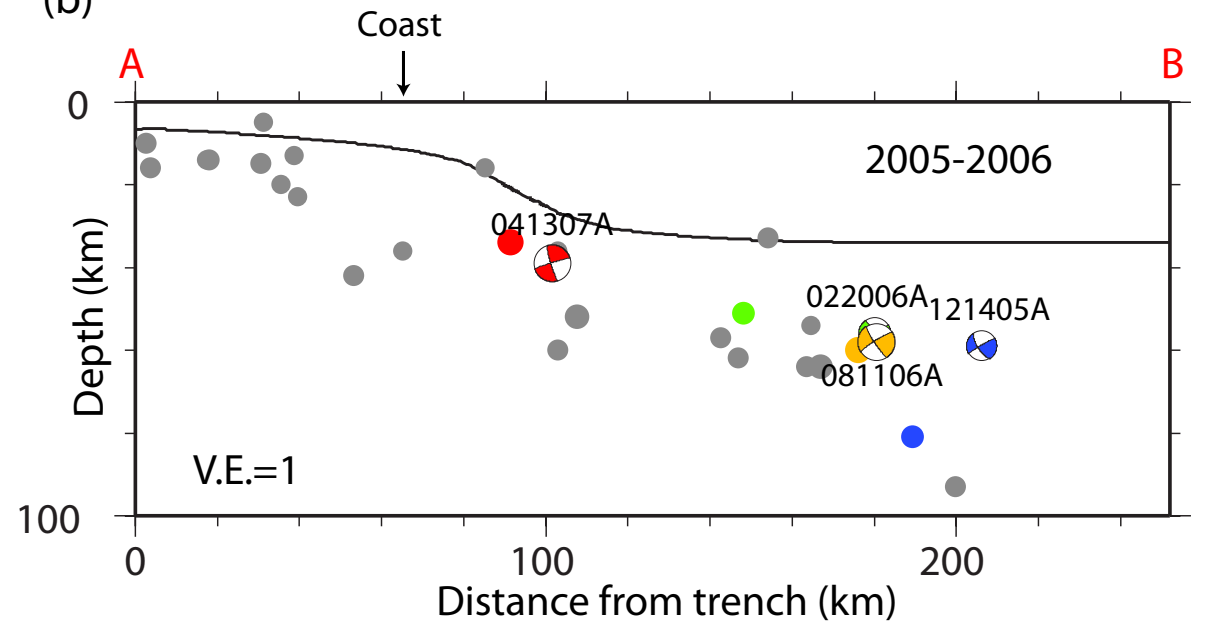

Fig. 7. (a) Map view of seismicity in Guerrero, 2003-2006. Extensional earthquakes "121405A", "022006A" and "081106A" are colored in blue, green and orange, respectively. A recent thrust earthquake "041307A" following the 2006 transient is also shown. (b) Seismicity, 2005-2006, within the dashed-line box projected to a vertical cross-section along AB. Legends3itre the same as in Figure 3. 


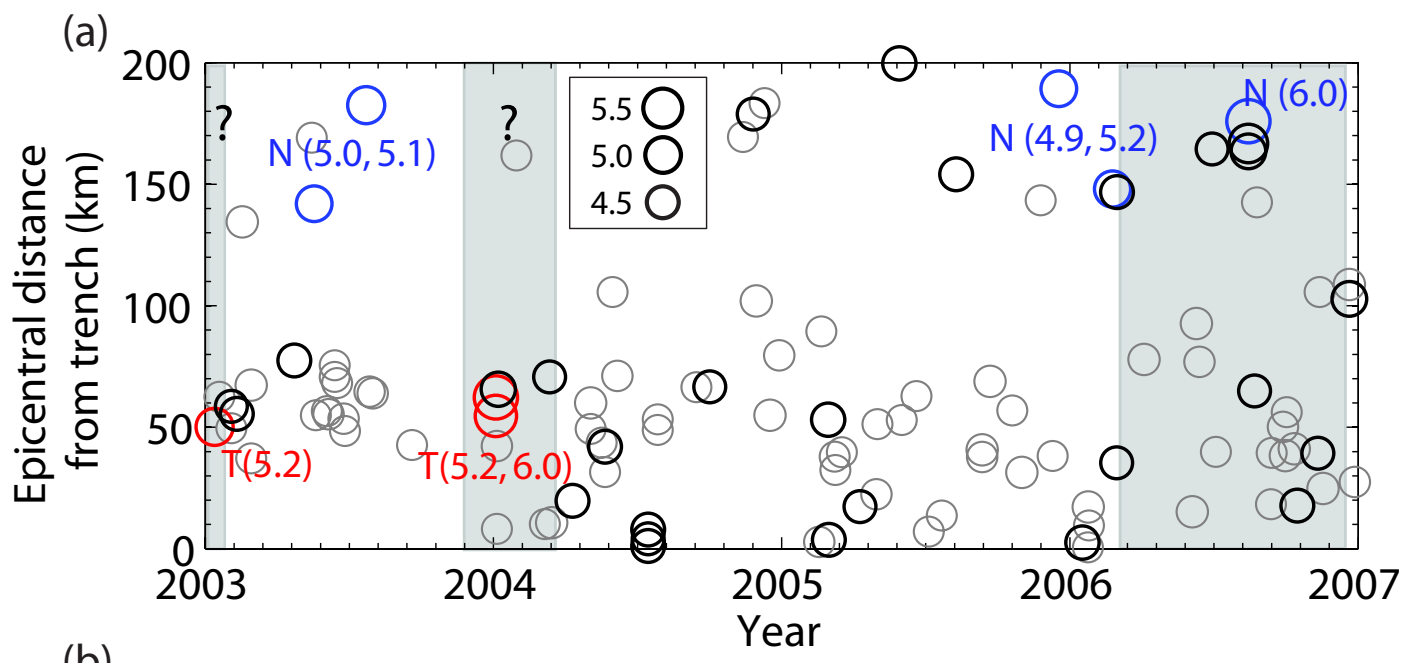

(b)

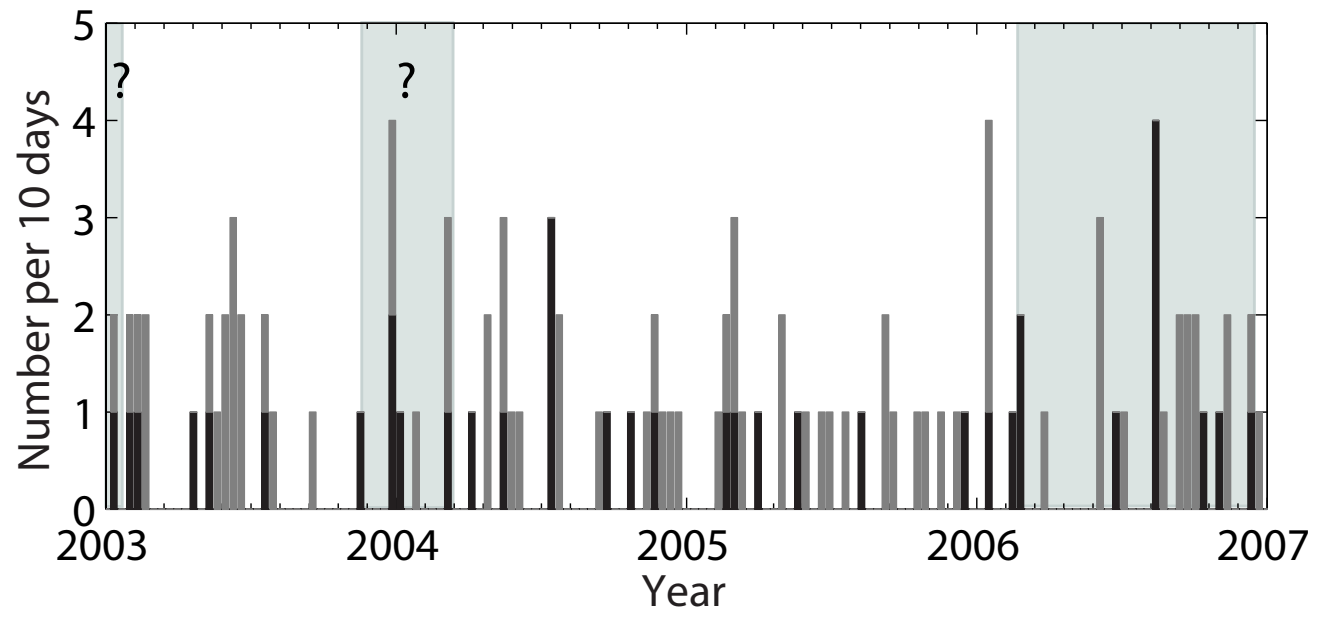

Fig. 8. (a) Epicentral distance from trench and (b) seismicity rate, 2003-2006. NEIC events above 4.2 are shown here. Symbol representations are the same as in Figure 4. The transient marked for early 2003 is continued from late 2002 , as shown in Figure 6. 